\title{
Different Methods of Accident Forecast Based on Real Data
}

Gajendran C, Serin VK, Seenu SG, Swati P

Karunya University, Coimbatore, Tamil Nadu, India

\begin{abstract}
Loss of lives through road accidents are increasing day by day as there is increase in the number of motor vehicles on the road which has created a major problem. This paper discusses about three types of accident prediction model such as "System Dynamic Model, Fuzzy logic and Bayesian Method". Investing in transportation sector leads to betterment of basic infrastructure at the development of a country. The Complex, Dynamic and Non-linear interaction can be understood using system dynamic model. Fuzzy logic deals with occurrence of sets and elements. Fuzzy model compresses of four sub process: Fuzzification, Rule Production, Composition or Aggregation and Defuzzification. Bayesian refer to methods in probability and Statics which has held to model the interaction between road geometry, traffic characteristics and accident frequencies by means of linear regression model.
\end{abstract}

Keywords: Accident predicition modal; Accidental factors; Accident frequencies; Fatal accidents; Road geometric; Traffic condition

\section{Introduction}

India is a second largest populated country in the world with 1.252 billion of people. Transportation sector plays the vital role in Indian economy. There is a tremendous growth of motor vehicles due to the rapid population growth and increasing economic and technological activities. This is one of primary factors responsible for the road accidents in many metro Politian cities in India. There is 1.34 lakh fatalities road accidents every year. An accident prediction model is a mathematical model which describes the relationships between road accident frequencies and various traffic conditions, road geometric features, environmental factors as well as driver's behaviours. Accidents are not as uncontrollable as the weather, nor do they defy systematic study. Study of accidents based on "macro "scale includes the tabulation of numbers and rates unrelated to true risk, which is meaningless to the general public, including drivers and passengers [1]. The main reasons for road accidents are due to improper interactions between the vehicles, other road users and road way features. The situation that leads to improper interactions may be as a result of the complex inter play of number of factors such as pavement characteristics, geometric features, traffic characteristics, road users behaviour, vehicle design, drivers characteristics and environmental aspects. Thus the whole system of accident occurrence is a complex phenomenon [2]. The quality of the data collected in a particular study also has a large effect on the accident predicting equations developed. Care must be taken in collecting data otherwise the results of a study will be of little worth [3]. In different cities such as Delhi, Mumbai, Chennai, Ernakulam, there have been number of studies carried out on road safety. It is estimated that throughout the world 1.3 million persons die and 50 million persons get injured every single year in road accidents $[4,5]$.

\section{Accident Prediction Models}

\section{System dynamic road accident prediction model}

To understand the behaviour of complex system, system dynamics is used. System dynamics is a computer-aided approach to policy analysis and design. System dynamics is a methodology, where in complex, dynamic and non-linear interactions in social systems can be understood and analysed and new structures and policies can be designed to improve the system behaviour. System dynamics methodology has been employed in many occasions to analyse the transport field [6]. It shows how system dynamics modelling techniques can be employed in various capacities to analyse traffic systems and accidents on different levels [7].
As the road accident prediction studies involve various complex systems namely the human, road, vehicle and all other environmental factors, it is vital to develop dynamic simulation model to understand the interactions between the various complex systems. In this study, the system dynamics simulation software namely STELLA was used. The model has also been validated with the real world accident records [8]. The system dynamic model combines both qualitative and quantitative aspects and aims to enhance the understanding of complex systems to gain insights into system behaviour [9]. For instance, the Centre for Public Policy and Administration of the University of Utah is using the system dynamic model to estimate welfare reform initiatives [10].

The number of $A \& E$ patients is not static. It means that even if the variables themselves remain constant, the coefficient values of the variables will change over time. Now, we cannot answer the question of "what is the real cause of the difference," but we trust in the regression technique which indicates the affecting factors. Likewise, the system dynamic model works as a "micro world," making it is easy to simulate more than one factor at the same time [11].There have also been studies that focus on the effects of driver's age, education and experience in traffic safety [12] the role of alcohol in traffic accidents [13].

A study has been done by Nathimuthu and Parthibhan in Chennai, the capital city of Tamil Nadu. Road accident prediction model is done for both urban and rural road separately and here urban roads are considered. Chennai is the $31^{\text {st }}$ largest metro Politian in the world. It has the population of 8.9 million people. Data was collected from 2006 to 2010 from Chennai city traffic Police. The road accident prediction model was developed using Factors of human behaviours, vehicle factor and road factor. This model was developed using STELLA a System Dynamic Model software .The main objective for the studies is to predict the expected number of accidents from 2010-2020.

Methodology: This model considers Human factors, Vehicle factors, road factors, environmental factors and other factors for the accident causes. Three types of implementations of model like

*Corresponding author: Gajendran Chellaiah, Karunya University, Coimbatore Tamil Nadu India, Tel: + 91 9443368980; E-mail: gajendran@karunya.edu

Received April 07, 2015; Accepted July 13, 2015; Published July 23, 2015

Citation: Gajendran C, Serin VK, Seenu SG, Swati P (2015) Different Methods of Accident Forecast Based on Real Data. J Civil Environ Eng 5: 180. doi:10.4172/2165-784X.1000180

Copyright: (c) 2015 Gajendran C, et al. This is an open-access article distributed under the terms of the Creative Commons Attribution License, which permits unrestricted use, distribution, and reproduction in any medium, provided the original author and source are credited. 
Human factors, Vehicle factors and Road factors combines to form this simulation model. Table 1 explains the factors identifying the road accident model. Information about the flow of events should be entered by a simulation expert.

Relationship was established on several variables responsible for causing road accidents. Some variables found increase in the number of accidents and less number of variables is meant for reduction of accident. The road accident can be reduced by providing driver training, issuing of license system, removing of aged vehicles and controlling of drunken drivers, over speeding and enforcement of strict traffic rules. The model is validated by comparing the predicted accident values with actual accident values for the years 2010, 2011 and 2012. It is found that the percentage of variation is ranging from -1.12 to +5.44 . In this study, more detailed classification standard and predicted accidents are applied. If the results are used for the research, it is easy to execute safety evaluation about various alternatives in case of planning new road business and calculate results in detail for accidents reduction [8].

\section{Network road accident prediction model fuzzy}

A Fuzzy set is defined as a set which has full membership or no membership to its element. The challenge faced by fuzzy theory is the rejection of any object belonging to a single set. It has been suggested to go for partial belonging of any object to different subset of a universal set. Common-sense linguistic labels like cold-warm-hot, heavy-light, low-medium-high etc. can be represented by fuzzy sets. Fuzzy logics have also been used for prediction of psychological status of working groups [14]

The principles of fuzzy logics, fuzzy clustering, and fuzzy modelling are of rich structure and offer a fruitful data-driven approach to model relations between physical and psychophysical measures [15]. The reason why fuzzy logics are accepted is that it provides a constructive way of turning qualities into mathematics. Inaccurate and/or incomplete expert knowledge is formulated with help of a set of ifthen rules [15].The fuzzy sets $\mathrm{Ci}$; in are supposed to be represented by clusters. The partitioning of the data into clusters is automatically done by cluster analysis [16]. The fuzzy model is a support tool based on modern technology, which Woodcock and Galer [17] asked for.

Fuzzy neural network (FNN) is a concept that integrates some features of the fuzzy logic and the artificial neural networks (ANN) theory. It based on the integration of two complementary theories. Purpose of the integration is to compensate weaknesses of one theory with advantages of the other [18]. On the one hand, it enhances the model interpreting ability of the neural network by making use of the

\begin{tabular}{|l|l|l|l|}
\hline Human factor & Road factor & Vehicle factor & Other factor \\
\hline Drivers behaviour & Vertical alignment & Breaking system & Rain \\
\hline Pedestrians & Sight distance & Lighting system & Snow \\
\hline Road users & Carriage width & Body its feature & Weather \\
\hline Age of driver & $\begin{array}{l}\text { Width and } \\
\text { Shoulder }\end{array}$ & Tyres & Climate \\
\hline Sex of driver & Signs and marking & Vehicle inspection & Pollution \\
\hline Marital status & Junction design & Vehicle maintenance & Population \\
\hline Training of drivers & Pavement surface & Age of vehicle & Birth rate \\
\hline Alcohol and Drugs & Median width & Number of reg vehicle & Death rate \\
\hline Fatigue & Bridges and culvert & & In-migration \\
\hline $\begin{array}{l}\text { Use of helmet and } \\
\text { safety belt }\end{array}$ & $\begin{array}{l}\text { Formation } \\
\text { Delineators and } \\
\text { guard rails }\end{array}$ & & Out-migration \\
\hline Physical factors & Street lighting & & Encroachments \\
\hline \multicolumn{2}{|l|}{ Table 1: Factors leading to road accidents [6]. } \\
\hline
\end{tabular}

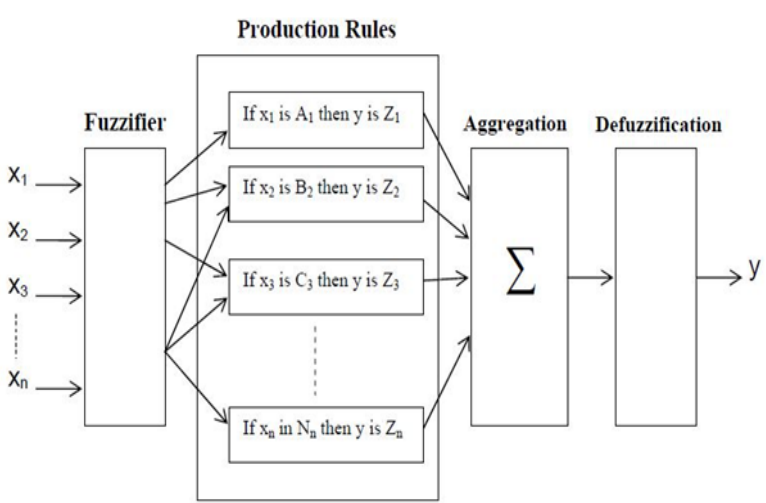

Figure 1: Schematic diagram of a fuzzy inference system [34].

interpreting ratiocination ability of the fuzzy system. On the other hand, it overcomes the dependences of the fuzzy technology on the advice of experts and the non-self-adaptability of the fuzzy sets by taking advantage of the self-learning functions of the neural network [19].

The case study has been carried out in Izmir metropolitan city. Traffic inspection department of Izmir were assigned to carry out the case study of the urban region. With the help of ArcGIS special analysis tool boundary of the study is done. The research was carried out for 20052007. In the year 2005,42792 traffic accidents with information such as location, time, road or weather condition type of accidents and number of killed or injured people etc. was recorded by TIDI. Mat lab is used for the Fuzzy Analysis.

Methodology: Fuzzy model compresses of four sub process and they are Fuzzification, Rule Production, Composition or Aggregation, Defuzzification. The Figure 1 mentioned below describes the process. It also consists of three explanatory variables such as traffic variables, geometric variables, environmental variables. Traffic variables include traffic flow, average speed and average gap between vehicles. In geometric variables, variables like road width number of lanes, number of minor accesses and percent of medians. Environmental variables, variables such as number of bus staff and weather conditions are used. The model result was examined in detail. It helped to differentiate streets as safe or risky over the time zones. All the testing and calibration input data helped in finding out the output results and these results leads to four levels;

$$
\begin{array}{ll}
\text { o } & \text { High safety level (HSL) } \\
\text { o } & \text { Low safety level (LSL) } \\
\text { o } & \text { Low risky level (LRL) } \\
\text { o } & \text { High risky level (HRL) }
\end{array}
$$

\section{Prediction of road accidents based on Bayesian method}

The most common approach applied in early works is to model the interaction between the road geometry, traffic characteristics and accidents frequencies by means of multiple linear models [20]. Bayesian refers to methods in probability and statistics named after Thomas Bayes, in particular method related to statistical inference. Accident risk is considered based on three major dimensions such as the exposure, the accident and injury occurrence probabilities and the corresponding consequences. The most common approach applied in early works is to model the interaction between road geometry, traffic 
characteristics and accident frequencies by means of conventional (multiple) linear regression models.

In such studies, univariate counting models for only one single model response variable are used, implying, for example that the number of accidents corresponding to different degrees of injury severity are modelled separately without taking into account the dependencies that exist between them [21,22]. Such dependencies are considered in more recent studies where the different response variables are modelled jointly using multivariate modelling techniques [23-25]. Bayesian inference is the mathematical formulation of the Bayesian interpretation of probability. This is representing the process of fitting a probability model to a set of data and summarizing the result by a probability distribution on the parameters of the model and on predictions of new observations [26]. The first in terms that subjective probabilities are assigned based on the outcome of an experiment, and the latter in terms of symmetry considerations [27]. Full Bayes approaches also enable more detailed inference, adding more flexibility in selecting prior distributions [28] in incorporating different theoretical models, e.g. models for lane changing behaviour [29]. To better fit the crash data, some researchers [30-32] applied hierarchical data analysis techniques to deal with the multilevel data structures, while some others [33-35] employed the zero-inflated count model to account for the excess zero crash occurrences [36].

The case study has been conducted in the entire Austrian rural motorway network where the data was collected on number of injured road way users, injury accidents events and risk indicating variables were provided by the Austrian road safety board. The total length of the investigated road network is $3642 \mathrm{~km}$ for which the data was provided for both driving directions separately.

Methodology : This methodology uses a combination of three statically methods.1) Gamma updating of the occurrence frequencies of injury accidents and injured road users, 2) hierarchical multivariate Poisson-lognormal regression analysis taking into account correlations amongst multiple dependent model response variables and effects of discrete accident count data e.g. over-dispersion, and 3) Bayesian inference algorithms, which are applied by means of data mining techniques supported by Bayesian Probabilistic Networks.

The proposed methodology is composed of six major steps.

- Identification and determination of the response variables and risk indicating variables.

- Subdivision of road network into home genius segments.

- Gama-updating of the response variables.

- The development of multi variate Poisson-lognormal regression model for the description of the relationships between risk indicating variables and the response variables.

- Construction and parameter learning of the BPN.

- Prediction of the expected number of response variable events that is the expected number of injury accidents.

\section{Accident Model Variable Determination}

This contain of two types they are; model response variable and risk indicating variable which are shown in Figures 2 and 3 respectively CHAR (exit corridors, intersection, tunnels and normal/open doors), AADT (Annual Average Daily Traffic), HGV (Heavy Good Vehicles), Bends, SLP (Percentage of the upwards or Downward gradients (slope)), LAN (Number of Driving lanes), SPD (Signalized Speed Limit,

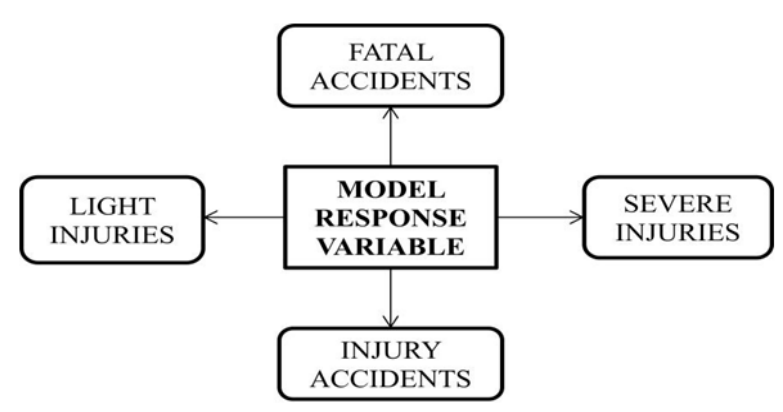

Figure 2: Model response variable.

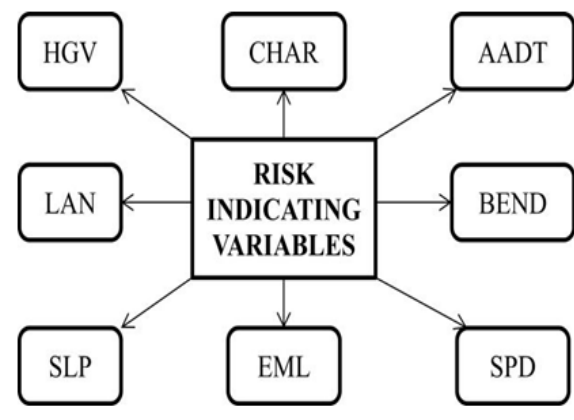

Figure 3: Risk indicating factor

EML (Existed of Road Emergency Lanes). The networks are developed by combining both, hierarchical multivariate regression analyses for the assessment of prior inferences and modern data mining techniques to adapt the Bayesian Probabilistic Networks to the available data. Even Though some regression coefficients appear to be statistically not significant for some combination of risk indicating variables and response variables, all variables are kept as input parameters for the model since they are significant for other combinations.

\section{Conclusion}

Comparable evaluation of road safety audit, Road safety Inspection and Roads safety impact assessment were the traditional methods for the road safety. Even scenario analysis is also used as an approach for the road safety. Cost and time required are the main disadvantages. In this paper we have discussed about three methods which are economic and having a better time management with a proper data provided.

The first paper we discussed was system dynamic model which is computer aided program which helps in design and analysis of the provided data. This method is used when the behaviour of data is complex and nonlinear. Its flexibility and handling of complex relationships are the main advantage of the system. Another method which can handle flexible, nonlinear and complex problem is fuzzy logic. Human communication is the basis of fuzzy logic. This method can blend with traditional control techniques. It is more preferable than other conventional methods due to its simple reasoning based on mathematics. Even though it is suitable for dealing with complex system, probabilistic techniques are used frequently. Next technique, probabilistic technique so called as Bayesian. Empirical bayes method is almost same as Bayesian Probabilistic Network which is also an accident prediction method. This method helps in displaying and 
conveying the problem in a Comprehensive and understandable manner. These methods describe the investigated problems in effective manner. As the data provided and each person's view of interest the methods can be chosen.

\section{References}

1. Desai MM, Patel AK (2011) Road Accidents Study Based On Regression Model: A Case Study of Ahmedabad City.

2. Chakra borty S, Roy SK (2005) Traffic accident characteristics of Kolkata Transport and Communications Bulletin for Asia and the Pacific 74: 75-86.

3. Turner S (1996) Estimating Accidents in a Road network. PhD Thesis, University of Canterbury, New Zealand, pp. 6-7.

4. Ye X, Liu T, Ye Y (2015) Enhanced grain refinement and Microhardness of Ti-Al-V alloy by electropulsing ultrasonic shock. J Alloys and Comp 621: 66-70.

5. Ye X, Yang Y, Tang G (2014) Microhardness and corrosion behaviour of surface gradient oxide coating on the titanium alloy strips under high energy electro-pulsing treatment. Surf Coat Tech, 258: 467-484.

6. Lechón RF (2010) Road safety strategies: An analysis with system dynamics.

7. Nachimuthu K, Partheeban P (2013) Development of a Road Accident Prediction Model Based on System Dynamics Approach. IJAR 3.

8. Srijariya W, Riewpaiboon A, Chaikledkaew U (2008) System Dynamic Modeling: An Alternative Method for Budgeting 11: 1.

9. Emmi CP, Forster BC, Mills IJ (2007) A system dynamics model of welfare reform in Utah: Phase II Final Report.

10. Senge PM. (1990) The Fifth Discipline: The Art and Practice of the Learning Organization. Doubleday, New York

11. Levy D (1990) Youth and traffic safety: The effects of driving age, experience and education. Accident Anal Prev 22: 327-334.

12. Trevisani CF, Bernardi M (2007) Alcohol misuse and traffic accidents. The Lancet 369: 463-464.

13. Dishkant $H$, Vasilenko $V$ (1992) New version of fuzzy logic, fit for the prediction of the psychological statea. In: Terano T, Sugeno M, Mukaidono M, Shigemasu (eds.) Fuzzy Engineering toward Human Friendly Systems. IOS Press, pp. $115-121$

14. Hanson L, Wienholt W, Sperling L (2010) A control handling comfort mode based on fuzzy logics.

15. Oppner HF, Klawonn F, Kruse R, Runkler T (1999) Fuzzy Cluster Analysis. Wiley, New York.

16. Woodcock A, Galer Flyte M (1998) Supporting ergonomics in automotive design. Int J Vehicle Design 19: 504-522.

17. Zhang NY, Yan PF (2004) Neural Network and Fuzzy control. Tsinghua University Press, Beijing, pp. 31-45
8. Modi PK, Singh SP, Sharma JD (2008) Fuzzy Neural Network Based Voltage Stability Evaluation of Power Systems with SVC. Appl Soft Comput 8: 657-665

19. Deublein M, Schubert M, Bryan TA, Kohler J, Faber MH (2013) Prediction of road accidents: A Bayesian hierarchical approach.

20. Park E, Lord D (2007) Multivariate Poisson-lognormal models for jointly modelling crash frequency by severity. Transportation Research Record. J Transport Res Board 2019: 1-6.

21. Hui L, Yunfei H, Ena Z, Kai S (2012) Prediction of Safety Objective of an Enterprise Using Fuzzy Neural Network.

22. Bijleveld FD (2005) the covariance between the number of accidents and the number of victims in multivariate analysis of accident related outcomes. Accident Anal Prev 37: 591-600.

23. Song JJ, Ghosh A, Miaou S, Mallick B (2006) Bayesian multivariate spatial models for roadway traffic crash mapping. J Multivar Anal 97: 246-273

24. Elvik R (2011) Assessing causality in multivariate accident models. Accident Anal Prev 43: 253-264.

25. Gelman A, Carlin JB, Stern HS, Rubin DB (2004) Bayesian data analysis. Chapman and Hall/CRC, Boca Raton.

26. Faber MH (2012) Statistics and Probability Theory: In pursuit of engineering decision support, Dordrecht, Springer.

27. Basyouny EK, Sayed T (2011) A full Bayes multivariate intervention model with random parameters among matched pairs for before-after safety evaluation. Accident Anal Prev 43: 87-94.

28. Ahmed KI (1999) Modeling Drivers' Acceleration and Lane Changing Behaviour $\mathrm{PhD}$, Massachusetts Institute of Technology MIT.

29. Shankar V, Mannering F, Barfield W (1996) Statistical analysis of accident severity on rural freeways. Accident Anal Prev 28: 391- 401.

30. MacNab YC (2003) A Bayesian hierarchical model for accident and injury surveillance. Accident Anal Prev 35: 91-102.

31. Chin HC, Quddus MA (2003) Applying the random effect negative binomia model to examine traffic accident occurrence at signalized intersections. Accident Anal Prev 35: 253-259.

32. Miaou SP (1994) The relationship between truck accidents and geometric design of road section: Poisson versus negative binomial regression. Accident Anal Prev 26: 471-482

33. Shankar VN, Milton JC, Mannering FL (1997) Modeling accident frequencies as zero-altered probability process: an empirical enquiry. Accident Anal Prev 29: 829-837.

34. Chin HC, Quddus MA (2003) Modelling count data with excess zeros. Socio Meth Res 32: 90-116.

35. Helai H (2007) thesis Bayesian Hierarchical Analysis On Crash Predictions Models 58.

36. Selvi O (2009) Traffic Accidents Predictions Based on Fuzzy Logic Approach for Safer Urban Environments, Case Study: Izmir Metropolitian area. 